\title{
TERMINOLOGIAS ALIMENTARES E SUA RELEV NCIA PARA AUTONOMIA E CONSCIENTIZAÇÃO DO CONSUMIDOR EM RELAÇÃO À COMPRA E CONSUMO
}

\author{
Patrícia Natalina dos Santos ${ }^{1}$ \\ ORCID: 0000-0001-6501-3847 \\ JENNifER Lima Costa ${ }^{2}$ \\ ORCID: 0000-0001-9485-3730 \\ Layla Barbosa Alves 3 \\ ORCID: 0000-0003-2861-5851 \\ Naiara Barbosa Carvalho 4 \\ ORCID: 0000-0002-6068-2328 \\ VANElle Maria da Silva 5 \\ ORCID: 0000-0002-0692-8382
}

1 Graduanda em Engenharia de alimentos pela Universidade Federal de Viçosa, Campus UFV - Florestal. E-mail: (patricia.natalina@ufv.br).

2 Graduação em Engenharia de alimentos pela Universidade Federal de Viçosa, Campus UFV - Florestal. E-mail: (jennifer.lima.costa@gmail.com).

3 Mestranda em Ciências e Tecnologia de Alimentos pela Universidade Federal de Viçosa. E-mail: (layla.alves@ufv.com).

4 Doutora em Ciência e Tecnologia de Alimentos pela Universidade Federal de Viçosa, professora Adjunto do curso de Engenharia de Alimentos da Universidade Federal de Viçosa, Campus UFV Florestal. E-mail: (naiara.carvalho@ufv.br).

5 Doutora em Ciência dos Alimentos pela Universidade Federal de Lavras, professora Adjunto do curso de Engenharia de Alimentos da Universidade Federal de Viçosa, Campus UFV - Florestal. E-mail: (vanelle.silva@gmail.com). 
Resumo: Este estudo é baseado no projeto de extensão "Terminologias empregadas em alimentos: conscientização do consumidor para sua autonomia no momento da compra", que teve como objetivo conscientizar 70 alunos de uma escola pública sobre termos alimentares: transgênico e irradiado, probiótico e prebiótico, diet e light, e glúten e integral. Inicialmente, para averiguar o conhecimento prévio dos alunos, foi aplicado um questionário sobre as definições dos termos. O mesmo questionário foi reaplicado ao final dos encontros a fim de avaliar o conhecimento adquirido por esses. Posteriormente, foram realizadas palestras sobre esses termos e ao final dessas foi realizado um jogo a fim de que fixassem o conteúdo. Ao final do projeto foi disponibilizada uma cartilha para os estudantes terem livre acesso a consultas sobre o tema. Diante disso, verificou-se que os jovens agregaram conhecimento sobre os termos abordados o que lhes possibilitou terem maior autonomia na compra e consumo desses produtos.

Palavras-chave: Alimentos para fins especiais. Novas tecnologias de conservação. Termos alimentares.

\begin{abstract}
This study is based on the extension project: "Food terminology consumer awareness of their autonomy at the time of purchase", which aimed to educate 70 students in a public school about food terms: transgenic and irradiated, probiotic and prebiotic, diet and light, and gluten and integral. Initially, to check the student's previous knowledge, a questionnaire about the definitions of the terms was applied. The same questionnaire was reapplied at the end of the meetings in order to evaluate the knowledge acquired by them. Subsequently, lectures were held on these terms and at the end of them a game was held to fix the content. At the end of the project, a booklet was provided for students to have free access to consultations on the subject. Given this, it was found that the youngsters added knowledge about the terms addressed which allowed them to have greater autonomy in the purchase and consumption of these products.
\end{abstract}

Keywords: Special purpose foods. New conservation technologies. Food terms.

Resumen: Este estúdio se basa en el proyecto de extensión: “ Tecnología alimentaria: conciencia del consumidor sobre su autonomia en el momento de la compra", que tenía como objetivo sensibilizar a 70 estudiantes em una escuela pública sobre términos de alimentos: transgénico y irradiado, probiótico y prebiótico, diet y light, gluten y integral. Inicialmente, para determinar el conocimiento prévio de los estudiantes, se aplicó un cuestionario sobre las definiciones de los términos. El mismo cuestionario se volvió a aplicar al final de las reuniones para evaluar el conocimiento adquirido por ellos. Más tarde, se realizaron conferencias sobre estos términos y al final de ellos se realizó um juego para arreglar el contenido. Al final de proyecto, se puso a disposición una cartilla, para que los estudiantes tengan acesso gratuito a consultas sobre el tema. Ante esto, se descubrió que los jóvenes agregaron conocimiento sobre los términos abordados que los permitieron tener uma mayor autonomia en la compra y consumo de estos produtos.

Palabras claves: Alimentos especiales. Nuevas tecnologías de conservación. Términos de comida. 


\section{INTRODUÇÃO}

Uma alimentação saudável e equilibrada proporciona crescimento e desenvolvimento adequados, otimiza o funcionamento de órgãos e sistemas e, consequentemente, pode atuar na prevenção de doenças. Cada fase da vida tem suas necessidades específicas, no entanto, a nutrição é igualmente fundamental em cada uma delas. $\mathrm{O}$ alimento é indispensável para que o ser humano possa crescer e se desenvolver, portanto, uma alimentação saudável durante a infância é muito importante para o crescimento e desenvolvimento adequados (SBP, 2012).

Em consequência dessa demanda, o consumo de alimentos industrializados tem aumentado, logo, novas tecnologias de processamento têm proporcionado uma maior diversidade desses em supermercados. Desse modo, há uma variedade de símbolos e termos técnicos veiculados nos rótulos que são utilizados para a comunicação com o consumidor. Assim, o conhecimento sobre o significado desses símbolos e termos é de extrema importância para o consumidor, com o intuito de proporcionar uma maior autonomia no momento da compra. Termos como diet, light, probiótico, prebiótico, transgênico, irradiado, glúten e integral se enquadram nessa categoria (LOUZADA et al., 2015; SILVA et al., 2018).

O consumo excessivo de produtos processados e ultraprocessados é reflexo das estratégias de marketing muito bem elaboradas e desenvolvidas pelas indústrias que controlam o setor a fim de persuadir o consumidor (SOARES, 2013; SILVA, 2015). Na perspectiva do marketing, o público infanto-juvenil é um dos grupos de maior interesse, por meio da promoção comercial, vistos não apenas como futuros, mas como atuais consumidores. Portanto, é importante aprofundar o conhecimento sobre a vulnerabilidade dos públicos a que se dirige a publicidade de alimentos e como se dão escolhas verdadeiramente autônomas, para fins de discutir a questão das responsabilidades envolvidas, e de como essas são concebidas, sob uma perspectiva ética, por parte de quem produz e veicula campanhas publicitárias destinadas a crianças e adolescentes (SILVA et al., 2017).

O rápido crescimento do consumo desses tipos de produtos tem como consequência direta o aumento da obesidade, diabetes e outras doenças crônicas que acometem tanto adultos quanto crianças e adolescentes. Em contrapartida, o processo de conscientização tem tomado força e os hábitos alimentares vêm mudando nos últimos anos. Observa-se um crescente aumento na busca por uma alimentação mais saudável, a população está se tornando mais preocupada quando o assunto é o impacto alimentar na qualidade de vida e a contribuição da alimentação no aumento da expectativa de vida (FERREIRA, 2017). 
Para o sucesso do processo de conscientização, a rotulagem dos alimentos é um canal de comunicação fundamental para auxiliar o consumidor a realizar suas escolhas alimentares de forma consciente. No entanto, as informações disponibilizadas, nesse canal, são, geralmente, difíceis de serem decodificadas por serem pouco abordadas em escolas, na mídia e em outros canais de informação, e interpretadas pelos consumidores. Fato que pode impactar diretamente em escolhas alimentares inadequadas, reforçadas muitas vezes pelo uso das estratégias de marketing persuasivas e enganosas (FERREIRA et al., 2015).

Portanto, verifica-se a necessidade de implementação de ações coordenadas entre o governo, a sociedade civil organizada, as instituições públicas e, ou privadas de modo a favorecerem o desenvolvimento de estratégias concretas que efetivem a rotulagem como um canal de comunicação que garanta ao consumidor o direito à informação completa e de fácil entendimento, conferindo assim autonomia no momento de sua compra (MARINS et al., 2014).

De acordo com os Parâmetros Curriculares Nacionais de Saúde (PCN) (BRASIL, 2016), mesmo que a educação em saúde seja responsabilidade de muitas outras instâncias, em especial dos próprios serviços de saúde, a escola ainda é a instituição que, privilegiadamente, pode se transformar num espaço genuíno de promoção da saúde. Além disso, nesse espaço é possível despertar o interesse dos alunos nessa faixa etária, por meio da aplicação de atividades lúdicas e outras ferramentas educacionais que promovam o aprendizado.

Desse modo, este trabalho teve como objetivo promover a conscientização dos adolescentes do ensino fundamental de uma escola pública estadual situada na cidade de Florestal-MG sobre termos alimentares corriqueiros (diet e light; transgênico e irradiado; probiótico e prebiótico; integral e glúten) presentes em alimentos.

\section{METODOLOGIA}

O projeto de extensão foi realizado em uma escola pública, estadual, situada na cidade de Florestal, Minas Gerais, nos meses de março a novembro 2018, com a participação de 70 alunos do oitavo ano do ensino fundamental, com faixa etária entre 13 e 15 anos, de ambos os sexos. O mesmo foi avaliado e aprovado pelo Comitê de Ética da Universidade Federal de Viçosa, processo n. 55445016.4.0000.5153/2018, cumprindo os requisitos para a sua publicação. 


\section{QUESTIONÁRIO DE DEFINIÇÃO DOS TERMOS}

No primeiro encontro, com duração média de 50 minutos, foi apresentado aos participantes o objetivo do projeto, bem como os Termos de consentimento livre e esclarecido (TCLE's), sendo um para os alunos assinarem, e outro para os seus responsáveis, já que esses eram menores de idade. Posteriormente, foi aplicado um questionário estruturado contendo oito perguntas para avaliar o conhecimento prévio dos alunos sobre as definições dos termos diet, light, prebiótico, probiótico, transgênicos, irradiados, glúten e integral. De acordo com as perguntas sobre os termos (Tabela 1), as respostas foram elaboradas a partir das definições especificadas nas legislações Portaria 27 (BRASIL, 1998a) e a Portaria 29 (BRASIL,1998b), RDC 02 (BRASIL, 2002), Portaria 2658 (BRASIL, 2003), LEI No 10.674 (ANVISA, 2003), RDC No 54, (ANVISA, 2012). Ao final do projeto o mesmo questionário foi reaplicado aos alunos, a fim de comparar o conhecimento prévio e o aprendizado adquirido por eles.

TABELA 1. RESUMO dAS PERGUNTAS DOS QUESTIONÁRIOS PARA OS ALUNOS E PARA OS SEUS RESPONSÁVEIS.

\section{Perguntas Realizadas no questionário para os alunos}

Qual a definiç̧ão correta para o termo diet?

Qual a definição correta para o termo light?

Qual a definição correta para o termo probiótico?

Qual a definição correta para o termo prebiótico?

Qual a definição correta para o termo transgênico?

Qual a definição correta para o termo irradiado?

Qual a definição correta para o termo glúten?

Qual a definição correta para o termo integral?

Os resultados dos questionários aplicados foram analisados por meio da análise descritiva e do teste de Wilcoxon para amostras pareadas $(\mathrm{p} \leq 0,05)$. Por meio desse teste, foi comparada a diferença da quantidade de acertos dos oito termos do primeiro questionário em relação ao último questionário, bem como a quantidade de acertos totais entre as duas etapas. Todos os procedimentos operacionais de análise foram realizados com auxílio do software SPSS $15.0^{\circledR}$ (Statistical Package for the Social Sciences) em versão licenciada. 


\section{PALESTRAS SOBRE OS TERMOS}

Durante cada encontro foram apresentados dois termos, divididos de acordo com a categoria dos mesmos, transgênico e irradiado, que se referem a alimentos advindos de novas tecnologias, diet e light, que são alimentos para fins especiais, probiótico e prebiótico, que são alimentos funcionais e por fim glúten e integral, que são alimentos para fins nutricionais, resultando em quatro encontros apresentados nos meses de abril, setembro e outubro de 2018, respectivamente, sendo que os dois últimos encontros ocorreram no mês de outubro. O conteúdo teórico para as palestras foi elaborado com base nas legislações Portaria 27 (BRASIL, 1998a) e a Portaria 29 (BRASIL,1998b), RDC 02 (BRASIL, 2002), Portaria 2658 (BRASIL, 2003), LEI No 10.674 (ANVISA, 2003), RDC No 54, (ANVISA, 2012), o qual abrangia as definições dos termos, exemplos de produtos com essas alegações, vantagens e desvantagens, além de curiosidades sobre os tipos de alimentos relacionados a cada terminologia alimentar apresentada. Os encontros foram realizados na aula de Ciências, sendo 30 minutos de explicação e 20 minutos de dinâmica, para isso era utilizado um projetor.

\section{AVALIAÇÃO DO CONHECIMENTO DE FORMA LÚDICA}

Ao final de cada palestra era conduzido o jogo de perguntas no qual os alunos puderam se voluntariar para respondê-las. Cada estudante teve, em média, dois minutos para responder as questões propostas que foram elaboradas de acordo com os estudos de Da Rosa Cachapuz e Silva (2007), Silva et al. (2010) e Rorato et al. (2006). Caso a resposta estivesse errada, era dada a chance para os demais integrantes da sala auxiliá-lo. Cada aluno teve a chance de responder uma única vez, de modo que ao longo dos encontros a maioria dos estudantes pudesse participar da dinâmica. Para não favorecer nenhum estudante, primeiro o aluno se candidatava a responder e só após isso era revelada a pergunta. As perguntas realizadas durante os encontros estão apresentadas na Tabela 2. As respostas foram transcritas e avaliadas pela equipe e os resultados foram expressos por meio de frequência de acertos.

Tabela 2. Perguntas ReAlizadas nos encontros durante o joco de perGuntas.

Perguntas Realizadas SObre os termos transcênico E IRRAdiado

1. Um alimento irradiado é perigoso para o ser humano? Ele é radioativo?

2. Cite pelo menos três exemplos de alimentos que podem passar pelo processo de irradiação.

3. Existe alguma restrição alimentar em relação ao consumo de alimentos irradiados? 


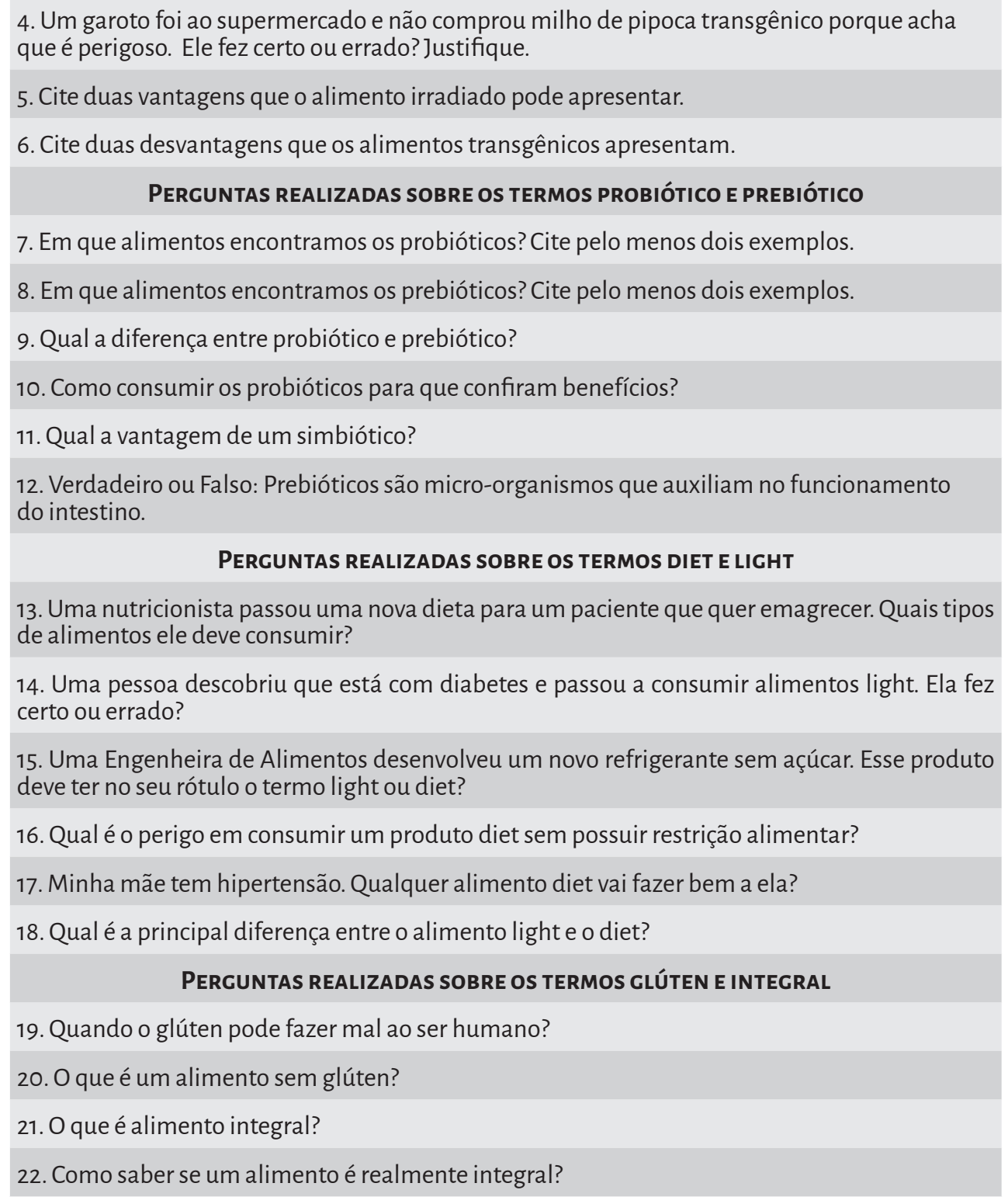

\section{CARTILHA}

Com o intuito de disponibilizar o conhecimento sobre esses termos para os participantes, bem como para os demais alunos da escola, foi elaborada uma cartilha utilizando a metodologia de Santos (2005). A mesma foi desenvolvida no programa livre Pixton no formato de quadrinhos para atrair a atenção dos jovens e facilitar a compreensão do conteúdo. A história ocorreu no ambiente escolar e se baseou em diálogos entre estudantes do curso de Engenharia de Alimentos com os alunos da escola estadual, esses buscavam compreender e conhecer mais sobre as 
terminologias abordadas, dois exemplares dessa foram deixados na escola para que todos os alunos possam consultá-las sempre que se fizer necessário.

\section{ABRANGÊNCIA DO PROJETO E COMPARAÇÃO COM AS VERSÕES ANTERIORES}

A fim de analisar o alcance desse projeto, que vem sendo executado desde 2016, foi realizada uma comparação com os trabalhos de Costa et al. (2018) referente ao projeto realizado em 2017 e de Souza et al. (2019) sobre o projeto executado em 2016, dos índices de acertos nos questionários, antes e após a realização das palestras, a fim de observar a importância da realização dessa conscientização, bem como a abrangência e eficácia do mesmo.

\section{RESULTADOS E DISCUSSÕES}

\section{QUESTIONÁRIO DE DEFINIÇÃO DOS TERMOS (PRÉ-PROJETO)}

Responderam ao questionário inicial, 70 alunos, sendo 40 desses do sexo feminino e 30 do sexo masculino, com faixa etária de 13 anos $\pm 1,5$ anos. A Figura 1 apresenta os resultados em relação à quantidade de acertos do questionário aplicado antes das palestras. Nenhum aluno errou todas as questões ou acertou sete ou oito questões, sendo oito o número total de questões. A maioria dos alunos acertou quatro questões (32,8\%) e a média geral da turma foi de $48,5 \%$ de acertos.

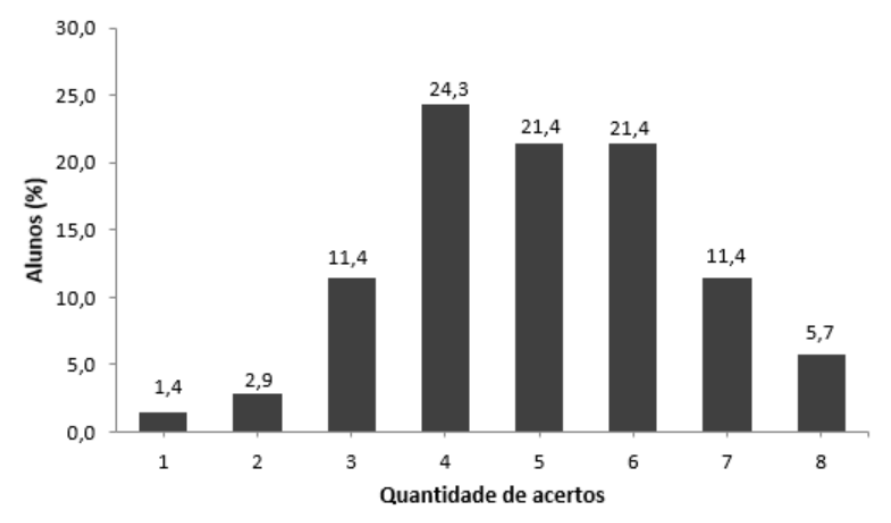

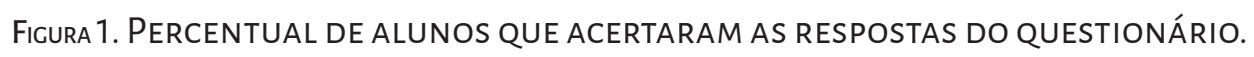

Ao avaliar a porcentagem de erros e acertos para cada termo alimentar de acordo com a Figura 2, verifica-se que o termo que obteve maior índice de acertos 
foi o integral (82,3\%), sendo a sua correta definição "Alimento mais nutritivo que os refinados, com fibras, vitaminas do complexo B e minerais"; seguido do diet $(69,1 \%)$ que são "Alimentos que apresentam ausência ou quantidades reduzidas de nutrientes (sal, açúcar, carboidratos)"; light (63,2\%) sendo definido como "Alimento que possui $25 \%$ de redução de calorias em relação ao alimento normal"'; prebiótico (48,5\%) que apresenta a seguinte definição "São carboidratos que estimulam seletivamente a proliferação e atividade de bactérias que fazem bem à saúde"; transgênico (39,7\%), definido como "Alimento geneticamente modificado que pode ou não trazer risco à saúde"; irradiado (30,8\%), sendo definido como "Alimento submetido ao tratamento de radiação pra maior conservação"; glúten $(29,4 \%)$, definido como "Proteína encontrada em cereais como trigo, cevada e centeio"; e o que obteve o menor índice de acertos foi o termo probiótico (23,5\%), que "São micro-organismos vivos que, quando ingeridos contribuem para o equilíbrio intestinal". Apenas os termos integral, diet e light apresentaram mais acertos que erros, que são os termos mais comumente encontrados na dieta alimentar, por exemplo, em produtos como iogurtes, chocolates e sucos, no caso de diet e light, e em produtos de panificação e torradas, no caso de integral.

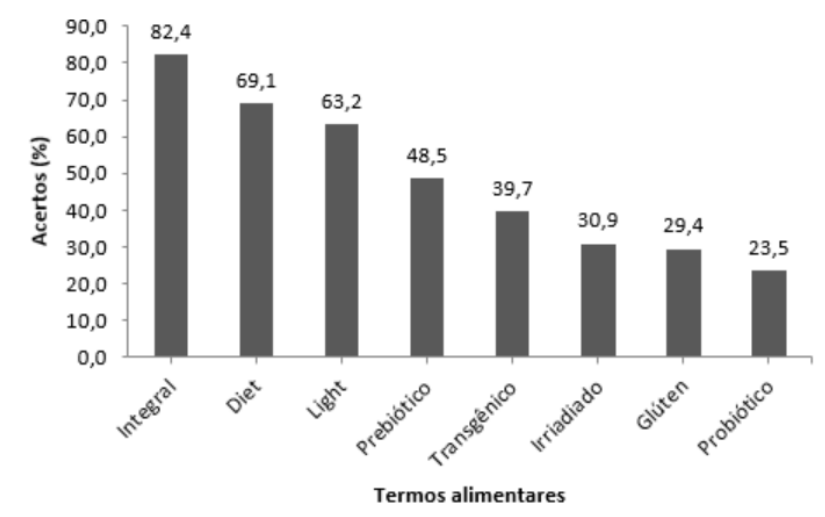

Ficura 2. PorcentaGem de ACERTOS POR TERMO AVALIADO.

Cavada et al., (2012) obtiveram um resultado similar ao deste projeto, em um estudo realizado com 241 consumidores, com faixa etária entre 18 a 40 anos, sendo a maioria do gênero feminino (77,5\%), na cidade de Pelotas - RS. O intuito do estudo era avaliar o hábito de leitura dos consumidores em relação aos rótulos dos produtos alimentícios. Em relação às informações mais procuradas na rotulagem destacaram-se: a data de validade (69,5\%); o valor calórico (39,0\%); o tipo e a quantidade de gordura (30,4\%); as vitaminas (16,6\%); o colesterol (14,9\%); light e diet (14,3\%); fibras (10,3\%); sódio (8,0\%); cálcio (5,7\%); alimentos específicos 
$(5,1 \%)$, e outras informações $(1,1 \%)$. Ou seja, entre as 11 categorias de informações consideradas mais importantes pelos consumidores, saber se o alimento é light ou diet está entre as seis informações mais relevantes. Enquanto as demais informações como o colesterol, valor calórico e tipo e quantidade de gorduras foram as que apresentaram maior porcentagem de indicações, e esses termos estão diretamente ou indiretamente ligados com os termos diet e light. Santos et al. (2015) realizaram um estudo com 210 adolescentes com faixa etária entre 13 e 18 anos, no qual $58,2 \%$ dos participantes indicaram o conceito correto para o termo diet e 57,0\% acertaram o conceito de light.

Em relação ao termo probiótico, o qual obteve menor índice de acertos, foi observado um resultado similar ao estudo realizado por Holanda et al. (2008). No estudo citado, avaliou-se o conhecimento de 198 estudantes de uma instituição do ensino superior sobre o termo probiótico, no qual foi detectado que a maioria dos participantes $(68,0 \%)$ desconhece a correta definição do termo probiótico. Apesar da porcentagem de acertos encontrada pelos autores para esse termo $(32,0 \%)$ ter sido maior que a encontrada neste projeto, essa diferença pode ser justificada pelo grau de escolaridade dos estudantes, uma vez que os participantes do projeto estão cursando o ensino fundamental.

\section{AVALIAÇÃO DO CONHECIMENTO DE FORMA LÚDICA}

Sobre os termos transgênico e irradiado a palestra contribuiu para um melhor entendimento, pois foram verificados 100,0\% de acertos no jogo de perguntas. Após o estudante ter respondido a pergunta, mesmo que de forma correta, as palestrantes repetiram a resposta correta a fim de fixar o conteúdo apresentado e sanar alguma dúvida que pudesse ter permanecido após as explicações. Quando foram questionados se um alimento irradiado é perigoso e radioativo eles responderam que não; na questão em que foi solicitado para citar três exemplos de alimentos que podem passar por irradiação, os participantes citaram banana, morango e mamão. Na pergunta sobre se existe restrição alimentar para o consumo de alimentos irradiados eles afirmaram que não existe; como vantagens dos alimentos irradiados (questão 5) eles citaram que o alimento dura mais e que tem menos perdas. Em relação às respostas dadas sobre transgênico, para a pergunta que criava uma situação no supermercado sobre um garoto que não comprou um milho de pipoca porque achava que era perigoso, os respondentes disseram que ele agiu errado, pois não existe comprovação de que os alimentos transgênicos são perigosos; no questionamento sobre as desvantagens dos transgênicos eles 
citaram o fato de não saber se faz bem ou mal à saúde e a possível seleção e evolução de pragas e doenças, ao serem submetidas ao contato com o transgênico.

A palestra também colaborou para um melhor entendimento sobre os termos probiótico e prebiótico, pois foram verificados 83,3\% de acertos no jogo de perguntas. Apenas quando responderam a pergunta de verdadeiro ou falso, que afirmava que prebióticos são micro-organismos que auxiliam no funcionamento do intestino os estudantes responderam de forma errônea, pois os mesmos confundiram prebiótico com probiótico na frase e não prestaram atenção ao ouvir e ler a questão. Entretanto, se comparada à dinâmica realizada na palestra sobre os termos transgênico e irradiado a porcentagem de acertos foi menor. Enquanto para as demais perguntas relacionadas aos termos eles responderam de forma correta, sendo essas: em que alimentos encontramos probióticos, os respondentes citaram Yakult ${ }^{\oplus}$ e Iogurte; em que alimentos encontramos os prebióticos, eles citaram maçã e aveia; em relação ao modo correto de consumir os probióticos os mesmos responderam que deve ser uma quantidade certa por dia e todos os dias para que tenha os benefícios esperados; para diferenciar probiótico de prebiótico eles consideraram como sendo os probióticos micro-organismos vivos e os prebióticos as fibras que os alimentam; quando questionados sobre a vantagem dos simbióticos eles responderam que esse alimento vai ter os benefícios tanto do probiótico quanto do prebiótico.

Foi constatado também um melhor entendimento sobre os termos diet e light, pois foram verificados $100,0 \%$ de acertos no jogo de perguntas, apesar de em alguns momentos os estudantes recorreram à ajuda de outro colega para finalizar a resposta. Na pergunta sobre que tipo de alimentos devem ser consumidos para emagrecer, eles responderam alimentos light e alimentos mais saudáveis no geral; na questão que falava sobre uma pessoa com diabetes consumir alimentos light eles alegaram estar errado, pois o diabético deve consumir o alimento diet, pois esse não apresenta açúcar. Sobre o caso da criação de um novo refrigerante sem açúcar, eles foram questionados sobre qual termo deveria estar no rótulo e os mesmos responderam que devia ser refrigerante diet. Quando perguntados sobre o perigo de consumir um produto diet sem possuir restrição alimentar, eles relataram que, os alimentos diet apresentam a substituição de ingredientes como o açúcar por outros ingredientes em maior quantidade, por exemplo, o sódio, então o consumo exagerado pode trazer problemas à saúde. Em relação à pergunta que relatava uma pessoa com hipertensão e questionava se qualquer alimento diet iria fazer bem a ela, eles responderam que não, que o alimento deveria ser diet em relação a retirada de sal. Por fim, os alunos definiram a diferença entre light e 
diet como sendo o primeiro a retirada de, no mínimo, 25,0\%, de um ingrediente e para diet essa retirada deve ser praticamente total.

Por fim, sobre os termos glúten e integral os alunos apresentaram 100,0\% de acertos. Quando questionados sobre quando o glúten pode fazer mal ao ser humano os mesmos responderam que ocorre quando a pessoa é celíaca. Já na pergunta sobre o que é alimento sem glúten, eles citaram que são alimentos com grãos como a arroz, a chia, o milho, ou seja, alimentos que não apresentam a proteína do trigo, chamada glúten. Em relação ao que é alimento integral, eles entenderam como sendo alimentos fabricados com o uso de grãos mais inteiros, e que têm mais nutrientes. Por fim, para saber se um alimento é realmente integral, eles responderam que deve ser consultada a lista de ingredientes, para saber se a farinha integral é a primeira da lista.

De forma geral, os resultados foram satisfatórios e demonstram que as palestras realizadas obtiveram sucesso ao passar o conteúdo para os alunos de forma compreensiva e esclarecedora. Além disso, a dinâmica realizada auxiliou na fixação do assunto abordado e no melhor esclarecimento sobre o significado de cada termo.

\section{QUESTIONÁRIO DE DEFINIÇÃO DOS TERMOS (PÓS-PROJETO)}

No último encontro foi reaplicado o mesmo questionário estruturado aplicado no início do projeto para avaliar o conhecimento que os alunos adquiriram sobre os termos explicados. A amostra de respondentes foi a mesma do questionário inicial. Na Figura 3 são apresentados os resultados em relação à quantidade de acertos do questionário aplicado. Nenhum aluno errou todas as questões e quatro alunos acertaram todas as questões. A maioria dos alunos acertou quatro questões $(24,2 \%)$ assim como no questionário inicial. Em relação à média geral da turma, observou-se um percentual de $62,3 \%$ de acertos, mostrando uma porcentagem 13,7\% maior quando comparada à média obtida no questionário inicial.

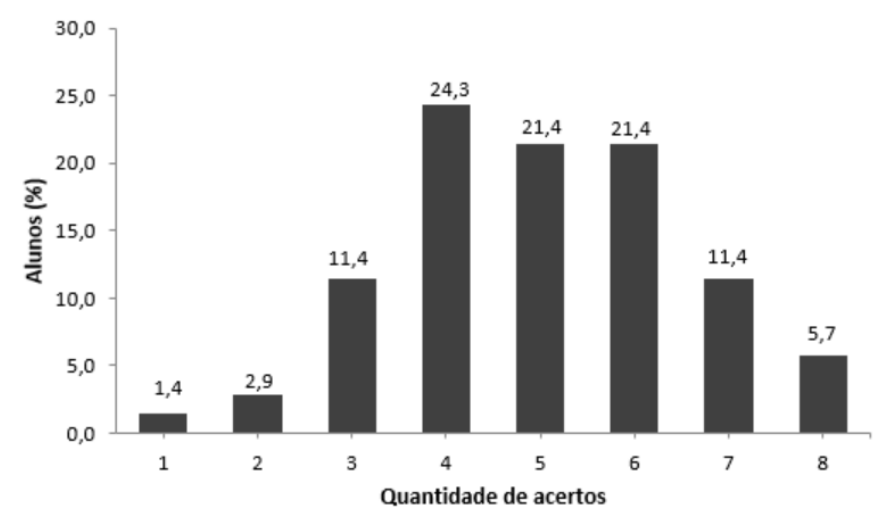

Ficura 3. Percentual de alunos que aCertaram as Respostas do QUeStionário REAPLICADO AO FINAL DO PROJETO. 
Ao avaliar a porcentagem de acertos para cada termo alimentar (Figura 4), verifica-se que o termo que obteve maior índice de acertos foi o integral (75,7\%), seguido do glúten $(70,0 \%)$, light (69,5\%), transgênico $(68,1 \%)$, diet e irradiado $(57,9 \%)$, probiótico $(55,0 \%)$, e o que obteve o menor índice de acertos foi o termo prebiótico $(42,0 \%)$. Todos os termos, exceto prebiótico apresentaram mais acertos que erros.

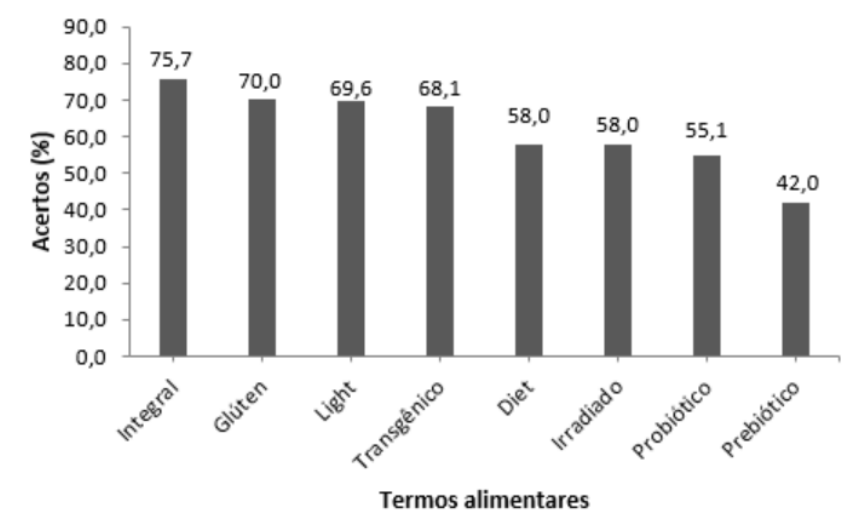

Ficura 4. PorcentaGeM de ACERTOS POR TERMO AVALIAdO NO QUESTIONÁRIO REAPLICADO AO FINAL DO PROJETO.

Para comparar estatisticamente as quantidades de acertos obtidos nos questionários inicial e final, realizou-se o teste de Wilcoxon para amostras pareadas, sendo seus resultados expressos na Tabela 3 .O curso, por sua vez, possibilitou um espaço para a construção de sentidos e (re)significação dos games para estes professores de língua inglesa em formação. Nesta perspectiva, acreditamos que a experiência com os games poderá propiciar aos professores novos olhares, contribuindo para uma formação e reflexões críticas.

Tabela 3. Valores obtidos no teste Wilcoxon para amostras pareadas.

\begin{tabular}{|l|c|c|c|}
\hline \multicolumn{1}{|c|}{ TERMOS } & \multicolumn{2}{|c|}{ TOtAL DE ACERTOS } & P-VALOR \\
\hline & ANTES DAS PALESTRAS & DePOIS DAS PALESTRAS & \\
\hline Ceral & 195 & 242 & $0,001^{*}$ \\
\hline Diet & 47 & 40 & $0,209^{\text {ns }}$ \\
\hline Light & 46 & 48 & $0,695^{\text {ns }}$ \\
\hline Probiótico & 17 & 38 & $0,001^{*}$ \\
\hline Prebiótico & 35 & 29 & $0,273^{\text {ns }}$ \\
\hline Transgênico & 28 & 47 & $<0,0001^{*}$ \\
\hline Irradiado & 22 & 40 & $0,001^{*}$ \\
\hline
\end{tabular}




\begin{tabular}{|c|c|c|c|}
\hline Integral & 56 & 54 & $0,637^{\text {ns }}$ \\
\hline Glúten & 18 & 45 & $<0,0001^{*}$ \\
\hline \multicolumn{2}{|c|}{${ }^{\text {ns }}$ diferença não significativa $(P>0,05)$} & \multicolumn{2}{|c|}{ *diferença significativa $(P \leq 0,05)$. } \\
\hline
\end{tabular}

No geral, observou-se que o conhecimento dos alunos sobre os termos foi maior $(\mathrm{P}<0,001)$ após as palestras indicando, dessa forma, que houve diferença significativa com relação à quantidade de acertos antes e após a realização do projeto. Com relação à quantidade de acertos referente a cada termo separadamente, nota-se que para os termos probiótico, irradiado, transgênico e glúten houve um aumento $(\mathrm{P}<0,05)$ no índice de acertos, mostrando assim que o projeto influenciou de forma positiva no aprendizado dos participantes. Todavia com relação aos termos diet, light, prebiótico e integral, observa-se que não houve diferença $(\mathrm{P}>0,05)$ entre a quantidade de acertos antes e após a realização do projeto, sendo que o termo diet no questionário inicial obteve 47 acertos enquanto que no questionário final caiu para 40 acertos, seguido de prebiótico que caiu de 35 para 29. $\mathrm{O}$ fato de alguns participantes faltarem nos encontros justifica a diferença não ter sido significativa para todos os termos, sendo que na primeira palestra participaram 68, na segunda 67, na terceira 62 e na quarta 70 alunos. Na terceira palestra, sobre os termos diet e light, observou-se o maior número de faltas dos alunos não sendo observada diferença $(\mathrm{P}>0,05)$ com relação à quantidade de acertos desses termos. Os resultados sobre os termos integral e prebiótico podem ser justificados pela quantidade de acertos inicial já ter sido grande, em relação ao primeiro questionário aplicado, enquanto o termo prebiótico gera muita confusão, por apresentar similaridade com o termo probiótico.

\section{COMPARAÇÃO COM OS PROJETOS ANTERIORES}

Ao comparar este presente trabalho com os artigos anteriores já publicados de Costa et al. (2018) e Souza et al. (2019), referentes à primeira e a segunda versão desse projeto, foi possível obter um panorama sobre o conhecimento adquirido pelos participantes, a partir dos resultados desses três trabalhos (Tabela 4). Essa observação não pôde ser feita com os termos glúten e integral, pois esses foram abordados apenas na última versão do projeto, logo, não há uma comparação específica para eles. Ao observar a Tabela 4 é possível verificar que o percentual de acertos não variou muito entre os anos de execução do projeto.

Além disso, pôde-se perceber que o nível de conhecimento dos estudantes manteve-se ao longo do tempo, apresentando uma melhora no conhecimento dos 
termos de forma geral, principalmente para os termos light, irradiado, transgênico e probiótico. Com isso, observou-se, a partir da comunicação entre os alunos, e dos alunos com as responsáveis pelo projeto que o mesmo foi de grande abrangência. Isso porque os participantes conseguem, a partir do conhecimento obtido, orientar os amigos e familiares e disseminar o que foi aprendido. Desse modo, o projeto atinge de forma construtiva não apenas as 241 pessoas participantes ao longo dos três anos de execução do mesmo, mas sim uma parte da comunidade escolar e familiar que não é possível dimensionar. No geral, observou-se que a porcentagem de acertos dos alunos sobre os termos foi maior após as palestras indicando, dessa forma, que houve esclarecimento e conscientização dos estudantes quanto aos termos abordados.

TABela 4. Comparação de ACERTOS dOS ALUNOS NO QUESTIONÁRIO ANTES E APÓS PROJETO.

\begin{tabular}{|c|c|c|c|c|c|c|}
\hline \multicolumn{7}{|c|}{ TOTAL DE ACERTOS } \\
\hline \multirow[t]{2}{*}{$\begin{array}{c}\text { TERMO } \\
\text { ALIMENTAR }\end{array}$} & \multicolumn{2}{|c|}{$\begin{array}{l}\text { VERSÃO 1-63 ALUNOS } \\
\text { (SOUZA ET AL., 2019) }\end{array}$} & \multicolumn{2}{|c|}{$\begin{array}{l}\text { VERSÃO 2-88 ALUNOS } \\
\text { (COSTA ET AL., 2018) }\end{array}$} & \multicolumn{2}{|c|}{ VERSÃO 3-70 ALUNOS } \\
\hline & Antes & Após & Antes & Após & Antes & Após \\
\hline Geral & $46,6 \%$ & $63,4 \%$ & $60,23 \%$ & $61,4 \%$ & $33,9 \%$ & $43,2 \%$ \\
\hline Diet & $68,0 \%$ & $60,0 \%$ & $97,0 \%$ & $39,0 \%$ & $69,1 \%$ & $58,0 \%$ \\
\hline Light & $38,0 \%$ & $78,0 \%$ & $56,0 \%$ & $71,0 \%$ & $63,2 \%$ & $69,6 \%$ \\
\hline Transgênico & $38,0 \%$ & $65,0 \%$ & $58,0 \%$ & $56,0 \%$ & $39,7 \%$ & $68,1 \%$ \\
\hline Irradiado & $48,0 \%$ & $57,0 \%$ & $45,0 \%$ & $63,0 \%$ & $30,9 \%$ & $58,0 \%$ \\
\hline Probiótico & $38,0 \%$ & $67,0 \%$ & $31,0 \%$ & $60,0 \%$ & $23,5 \%$ & $55,1 \%$ \\
\hline Prebiótico & $49,0 \%$ & $52,0 \%$ & $45,0 \%$ & $40,0 \%$ & $48,5 \%$ & $42,0 \%$ \\
\hline Glúten & $X^{*}$ & $X^{*}$ & $X^{*}$ & $X^{*}$ & $82,3 \%$ & $75,7 \%$ \\
\hline Integral & $X^{*}$ & $X^{*}$ & $X^{*}$ & $X^{*}$ & $29,4 \%$ & $70,0 \%$ \\
\hline
\end{tabular}

*não foram abordados os termos alimentares glúten e integral nas versões 1 e 2 do projeto de extensão.

\section{CARTILHA}

A cartilha referente ao Projeto foi elaborada e encontra-se disponível na biblioteca para que todos os alunos da Escola Estadual na qual se desenvolveu o trabalho tenham acesso. Esse trabalho foi feito de forma lúdica e criativa, em formato de uma revista em quadrinhos (Figura 5), a fim de despertar o interesse dos alunos e aumentar a atenção e atratividade do conteúdo. A partir disso, é esperado que os alunos continuem consultando o conteúdo, de modo que a 
cartilha auxilie em trabalhos escolares, por exemplo, bem como sirva de consulta e auxílio para estudantes que não participaram do projeto ou que não absorveram todo conteúdo apresentado, mas que têm acesso ao conteúdo na biblioteca. Logo, espera-se que um número maior de adolescentes possa propagar esse conhecimento para amigos e familiares.

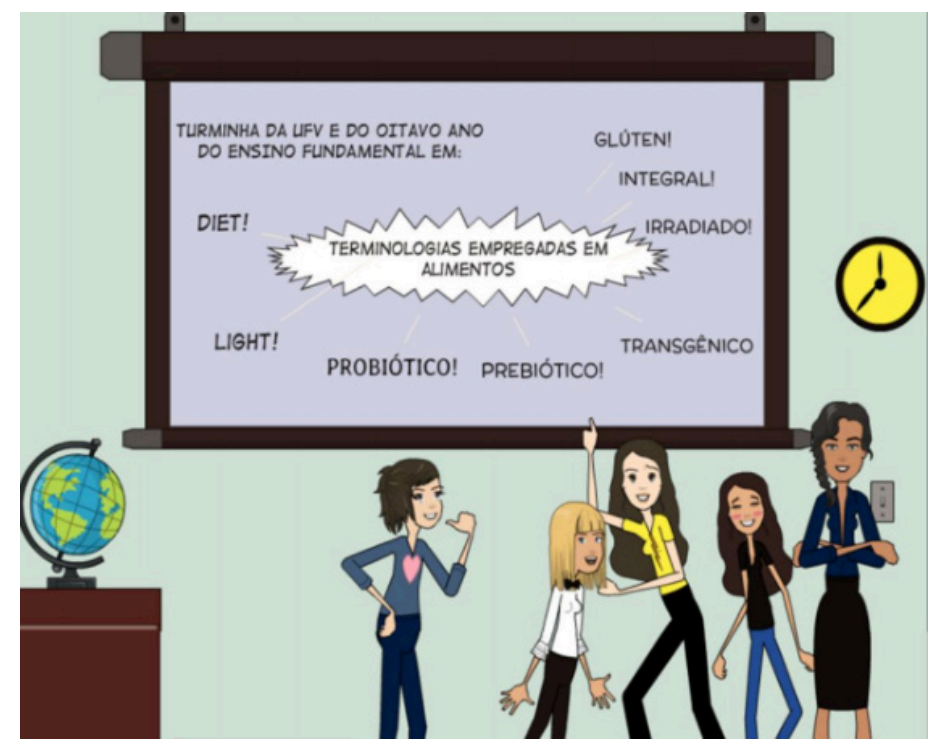

FIGURA 5. MODELO DA HISTÓRIA EM QUADRINHOS ELABORADA NA CARTILHA.

\section{CONCLUSÃO}

O projeto contribuiu para conscientização e esclarecimento sobre as terminologias veiculadas nos rótulos dos produtos alimentícios, bem como, para um consumo de forma adequada e hábitos alimentares mais saudáveis desses produtos, e por consequência uma maior autonomia no momento da compra. Desse modo, observa-se que esse projeto apresenta efetividade desde 2016, ou seja, 241 alunos foram conscientizados, de forma direta, sobre os termos alimentícios abordados no projeto.

Do ponto de vista acadêmico, o projeto viabiliza a oportunidade de estudantes de graduação do curso de Engenharia de Alimentos aprofundarem seus conhecimentos entre diferentes áreas do curso que abordam esses assuntos, tais como legislação, embalagens, conservação. O desenvolvimento do projeto e a realização das palestras contribuíram diretamente na formação profissional e pessoal dos envolvidos, por propiciar, além da oportunidade de transmissão de conhecimento e exercício de oratória, a responsabilidade de ser um consumidor consciente. 


\section{AGRADECIMENTOS}

À UFV pela concessão da bolsa PIBEX, a compreensão da direção da escola e aos alunos e pais por permitirem a participação e realização do projeto.

\section{REFERÊNCIAS BIBLIOGRÁFICAS}

COSTA, J. L.; SANTOS, T. J.; SANTOS, P. N.; SOUZA, R. L.; TORRES FILHO, R. A.; SILVA, V. M.; CARVALHO, N. B. A importância da conscientização do consumidor sobre termos alimentares. Cidadania em Ação: Revista de Extensão e Cultura, v. 2, n. 1, p. 139-151. 2018.

FERREIRA, J. S. G.; SILVA, Y.; MORAES, O. M. G.; TANCREDI, R. P. Marketing de alimentos industrializados destinados ao público infantil na perspectiva da rotulagem. Vigilância Sanitária em Debate: Sociedade, Ciência \& Tecnologia, v. 3, n. 2, p. 75-84, 2015.

LONGO-SILVA, G.; TOLONI, M. H. de A.; MENEZES, R. C. E.; ASAKURA, L.; OLIVEIRA, M. A. A.; TADDEI, J. A. A. C. Ultra-processed foods: Consumption among children at day-care centers and their classification according to Traffic Light Labelling system. Revista de Nutrição, v. 28, n. 5, p. 543-553, 2015.

LOUZADA, M. L. C.; MARTINS, A. P. B.; CANELLA, D. S.; BARALDI, L. G.; LEVY, R. B.; CLARO, R. M.; MOUBARAC, J.; CANNON, G.; MONTEIRO, C. A. Alimentos ultraprocessados e perfil nutricional da dieta no Brasil. Revista Saúde Pública, v. 49, n. 38, p. 2-11, 2015.

MARINS, R. M.; ARAUJO, I. S. de; JACOB, S. C. Vigilância Sanitária e direito à comunicação: a rotulagem de alimentos como espaço de cidadania. Vigilância Sanitária em Debate: Sociedade, Ciência \& Tecnologia, v. 2, n. 4, p. 86-95, 2014. 
SILVA, A. E. A. D.; SILVA, D. S. P. D.; OLIVEIRA, G. S.; MELO, M. C.; AZEVEDO, T. K. B. Crianças pré-escolares: uma revisão sobre o consumo de alimentos industrializados. Revista Humano Ser. Natal-RN, v. 3, n. 1, p. 19-32, 2018.

SILVA, D. A. C. DA; CUNHA, A. C. R. DA; CUNHA, T. R. DA; \& ROSANELI, C. F. Publicidade de alimentos para crianças e adolescentes: desvelar da perspectiva ética no discurso da autorregulamentação. Ciência \& Saúde Coletiva, v. 22, n.7, p. 2187-2196, 2017.

SOARES, S.A.; BORGES, A.R.; KOIKE, A.; ALMEIDA, K. A Força da Publicidade Infantil: Composto de Marketing e as Embalagens dos Produtos Alimentícios da Turma da Mônica. In: XXXVI Congresso Brasileiro de Ciências da Comunicação - Manaus, 2013.

SOCIEDADE BRASILEIRA DE PEDIATRIA. Manual de orientação para a alimentação do lactente, do pré-escolar, do escolar, do adolescente e na escola/Sociedade Brasileira de Pediatria. Departamento de Nutrologia, Rio de Janeiro, RJ: SBP, 3ª Ed, 148 p, 2012.

SOUZA, R. L.; CARVALHO, N. B.; COSTA, J. L.; SANTOS, T. J.; TORRES FILHO, R. A. Terminologias alimentares: conscientizando o consumidor para sua autonomia na compra. Rev. Ciência em Extensão, v. 15, n. 1, p. 114-129, 2019.

SOUZA, S. M. F. C.; LIMA, K. C.; MIRANDA, H. F.; CAVALCANTI, F. I. D. Utilização da informação nutricional de rótulos por consumidores de Natal, Brasil. Revista Panamericana de Salud Pública, v. 29, n. 5, p. 337-43, 2011. 
ANEXO

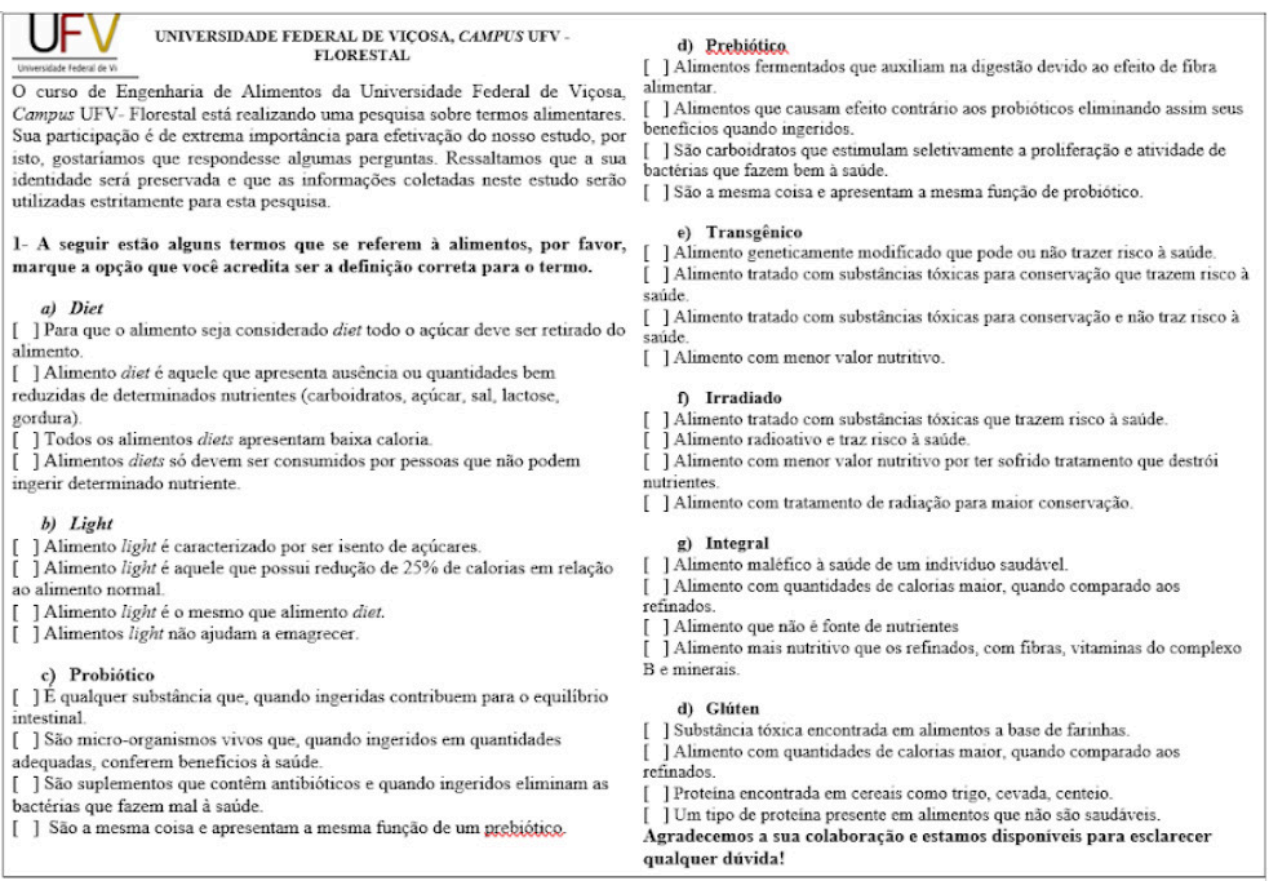

